\title{
Smart Waste Isolation and Monitoring Framework using IoT
}

\author{
Arathi B N, Shona M, Pankaja R
}

\begin{abstract}
Commonly, in our places, we see that the garbage canisters or dustbins set at open spots are over-burden. It leads to unhealthy conditions for individuals just as grotesqueness to that particular place leaving awful stench. To evade every single such circumstance, a venture called Smart Garbage Segregation and Monitoring System is developed. Interfacing of the dustbins with microcontroller based architecture is done, which involves sensors that shows the exact location of garbage on android device. At the point when waste achieves the threshold level the sensor sends the signal to the microcontroller unit which in turn forwards signal to the client via Wi-Fi along with location of bins utilizing GPS module. So consistent observing of trash canisters will keep the environment clean. The primary point of this task is to decrease human resources and efforts alongside the upgradation of a smart city vision.
\end{abstract}

Keywords: Solid Waste, Sensors, Wi-Fi, GPS, Arduino.

\section{INTRODUCTION}

Internet and its approach have turned into a vital part of the present lifestyle. It has transformed into a fundamental device in each edge. Because of the gigantic interest and the need, specialists started interfacing only computers into the web[1]. Conveyance over the internet has grown from client-to-client connection to device-to-device associations at the present time. There is fast development in transportation and home automation industries associated with IoT. This paper focuses on structuring the best in class audit on IoT. With the implementation of IoT, all the equipments whichever we use in our day to day life can be monitored and controlled. With the assistance of sensors in IoT, a larger part of procedure will be finished.

Sensors are effectively used all over to monitor the changes in the environment from the remote place. Smart waste Isolation and monitoring framework includes capacitive sensor,raindrop sensor and IR sensor to sense plastics, wet and dry materials.

The IR sensors are used to sense the different levels of garbage in the dustbins when its edge level is crossed. These details are additionally given to the microcontroller, the controller gives the subtleties to the transmitter module[2]. At the beneficiary area a mobile phone is associated with the Wi-Fi router so the details of the garbage bin are shown on our mobile device.

Revised Manuscript Received on September 25, 2019

Suma M.R, Electronics and Communication Engineering, DSCE, Bengaluru, India.

Dr. Madhumathy P, Electronics and Communication Engineering, DSCE, Bengaluru, India.

\section{LITERATURE SURVEY}

[1]. Waste administration framework based on IoT for shrewd urban communities by Prakash Prabhu gives thought regarding usage of realtime squander the board framework utilizing dustbins to check the whether the dustbins are filled or not. Information about every dustbin can be received from any of the places in this framework.

[2]. In waste receptacle checking framework utilizing combined technologies by Kanchan Mahajan the sensor is put in the rubbish container at extreme level, in the event that dimension crosses the threshold level by garbage in canister, at that point sensor will detect that and sends to ARM7 controller via ZigBee innovation.

[3]. RF(ZigBee) and GSM innovation used by City rubbish accumulation pointer. This paper gives transference of information to recipient side.

Road light and Garbage observing system using internet of things by Prof.R.M.Sahu, Akshay Godse, PramodShinde, Reshma Shinde incorporates garbage just as streetlight checking which avoids mishap amid night. This paper will lessen control utilization and manpower.

\section{DESIGN}

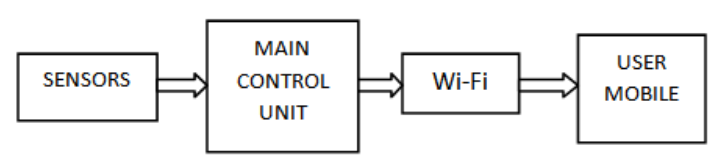

Fig -1: Block diagram of the Proposed model

Fig. 1 : demonstrates the overflow conditions of trash dustbins which is received by the client on his device. Sensor unit comprises of IR sensors, raindrop sensor and capacitive sensor. The main control unit comprises of Arduino; signal goes through Arduino and achieves the client portable through Wi-Fi.

\section{a. Detection of Garbage}

A wet sensor is utilized to recognize the wet waste, capacitive sensor is utilized to identify plastic waste and IR1 sensor is utilized to distinguish dry waste and IR2 sensor is utilized to distinguish the dimension of trash in the dustbin, it will distinguish whether the rubbish is at low, center or largest amount and generate simple signal. 


\section{b. Transmission of Signal}

It is required for the conversion of sensor's output signal from analog form into digital signal[7] The Then this signal is given to the Arduino which is the main control unit. GPS tracks the location of bins and sends to the Arduino, which processes the data after read it.

\section{c. Receiving of Signal}

Through Wi-Fi client mobile receives the signal that is transmitted from the control unit

\section{SYSTEM ARCHITECTURE}

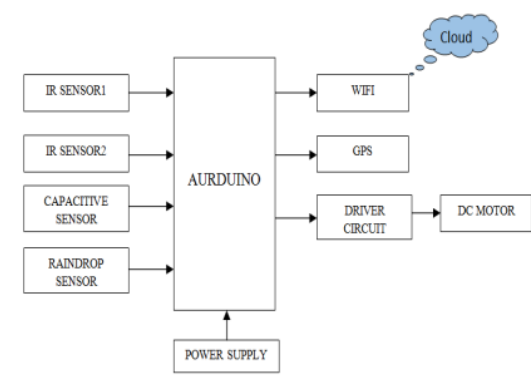

Fig -2: System architecture

\section{a. Sensor Unit}

The sensor unit comprises of wet sensor, IR sensors and capacitive sensors used to recognize types of waste i.e. wet, dry or plastic and garbage level in the dustbin.

\section{b. Arduino (Main Control Unit)}

Arduino is the the major control unit. The Arduino receives information about the area of dustbin and the sensor's output signal. The program used is an open source programming and simplifies the coding and transfers it on Arduino board[2]. From various sensors Arduino boards reads analog or digital input signals and transforms it into an output. For example, enacting an engine, association with the cloud and for various activities.

\section{c. GPS module}

GPS module is a small electronic circuit for Arduino. To get the position and height it interfaces with Arduino board.

\section{d. Wi-Fi module}

Wi-Fi Network interfaces PCs to one another, to the web and to the wired system[4].

\section{WORKING PRINCIPLE}

Fig .3.Working of proposed system

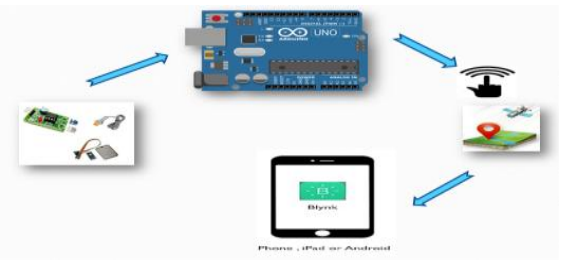

In this system we are proposing a novel method of separating the waste and informing the concerned person about the timely disposal of waste. Here initially the IR1sensor, raindrop sensor, and capacitive sensorare fitted to conveyor belt which detects dry, wet and plastic waste respectively.[3] As shown in the fig.3, the output signal of sensors is transmitted to Arduino board that controls rotational speed of DC Motor. Then IR2 sensor is fitted in bins that monitor the waste level in bin. Whenever the bin gets filled, it transmits signal to Arduino and GPS module connected to Arduino will track the location of the bin[5]. Then Arduino process the data and sends the details to the concerned person through Wi-Fi. The data is also stored and displayed on the Mobile Application.

\section{IMPLEMENTATION}

Implementation is the understanding of an application, or execution of one's thought, model, specification, algorithm, standard policy. Numerous implementations can be done for a specific specification or standard.

\section{ALGORITHM}

Step 1: Waste is thrown on the conveyor belt.

Step 2: Sensors read the value dry, wet, metal . DC motor shifts the particular bin

Step 3: Arduino will receive output signal of sensors and process it.

Step 4: IR sensor checks the garbage level of the bin, through Wifi data will be transmitted to blynk app

Step 5: Through GPS it gives the particular location of the bin and sends intimate signal to waste collector through blynk app.

\section{RESULTS}

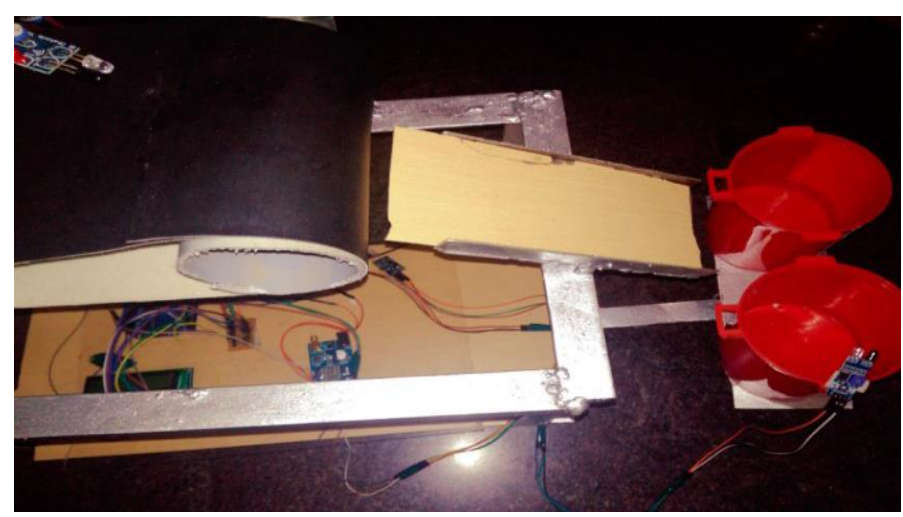

Fig 4: Top view of the model

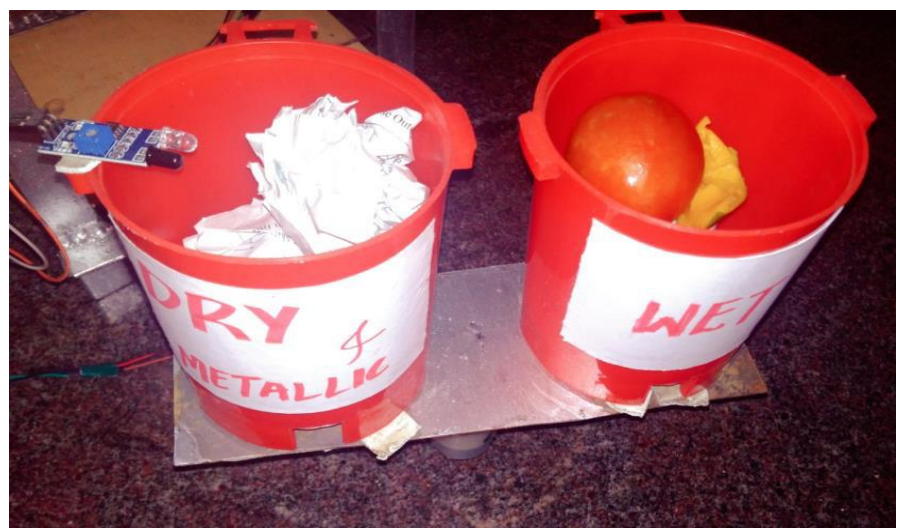

Fig 5: Collection of waste in bins

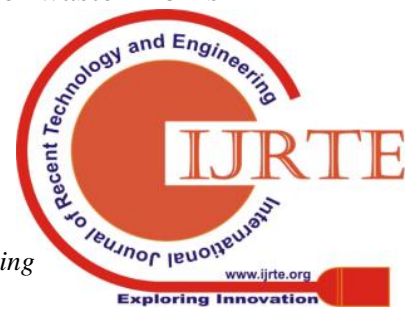




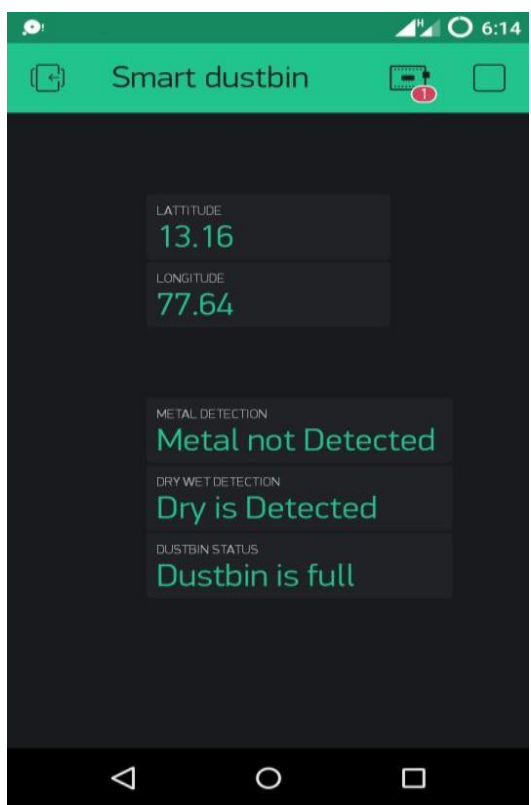

Fig 6: Snapshot of Database Details in blynk app

The snapshots of the proposed system is shown in fig.4, fig.5 and fig. 6 .

\section{CONCLUSION}

By executing this project we can be ready to isolate waste and screen the dimension of trash in the dustbins set at open spots, as per that we can assemble specific waste by which overflowing conditions of wastes can be avoided and the contamination and also different risks of wellbeing can be reduced. This structure decreases the number of outings of waste accumulation machines by reducing fuel wastage. Therefore, Smart waste isolation and checking framework utilizing IoT will make the trash accumulation more effectively.

\section{REFERENCES}

[1] Prakash, Prabhu, "IoT based management system for smart cities", International Journal of Innovative Research in Science, Engineering and Technology, vol 4, Issue 2, February 2016.

[2] Kanchan Mahajan, Prof J. S. Chitode,"Waste Bin Monitoring system Using Integrated Technologies", International Journal of Innovative Research in Science, Engineering and Technolgy(An ISO 3297:2007 Certified Organization) Vol 3, Issue 7, July 2014.

[3] Prof.R.M.Sahu, Akshay Godse, Pramod Shinde, Reshma Shinde," Garbage and Street Light Monitoring System using Internet of Things", International Journal of Innovative Resarch in Electrical, Electronics, Instrumentation and Control Engineering, Vol 4, Issue 4, 4 April 2016.

[4] M. Al-Maaded, N. K. Madi, Ramazan Kahraman, A. Hodizic, N. G. Ozerkar, An overview of Solid Waste Management and Plastic Recyling in Qatar, Springer Journal of polymer and the Environment, March 2012, Volume 20, Issue 1, pp 186-194

.[5] Raghumani Singh, C. Dey, M. Solid Waste Management of Thoubal Municipality, Manipur- a case study Green Technology and Environment Conservation (GTEC 2011), 2011 International Conference Chennai 21-24.

[6] Vikrant Bhor,'Smart Garbage Management System International Journal of Engineering Research \& Technology(IJERT), Vol 4 Issue 03, March201552000.

[7] Ms. S. N. Patil, Ms. S. S. Jagdale, Ms. A. T. Gharall Asst.Prof. R. B. Tapase,"Wireless ECG Monitoring. 